\title{
Itch, disease coping strategies and quality of life in psoriasis patients
}

\author{
Alicja Ograczyk ${ }^{1}$, Joanna Miniszewska², Anna Kępska ${ }^{1}$ Anna Zalewska-Janowska ${ }^{1}$ \\ 1Department of Psychodermatology, Medical University of Lodz, Lodz, Poland \\ Head of Department: Prof. Anna Zalewska-Janowska MD, PhD \\ Institute of Psychology, University of Lodz, Lodz, Poland \\ Head of Department: Prof. Eleonora Bielawska-Batorowicz PhD
}

Postep Derm Alergol 2014; XXXI, 5: 299-304

DOI: $10.5114 / p d i a .2014 .40927$

\begin{abstract}
Introduction: Psoriasis is a psychodermatological condition, so psychological factors can trigger and/or exacerbate skin lesions. Additionally, disease can be a source of stress and can worsen patients' quality of life (QoL).

Aim: To evaluate the relationship between medical (disease severity, itch) and psychological variables (disease coping strategies, QoL) in the psoriasis patients group.

Material and methods: The study comprises 60 in-patients of the dermatological ward (30 females and 30 males) with the diagnosis of psoriasis. Methods used: Psoriasis Area and Severity Index (PASI), Itch Severity Evaluation Questionnaire, Coping with Skin Disease Scale-SRS-DER, SKINDEX-29 questionnaire.

Results: The study demonstrated significant correlations between disease coping strategies, itch and quality of life. Women presented worse QoL (generally and in physical functioning). The older patients with a longer disease duration revealed QoL impairment.

Conclusions: The obtained results could help in identifying patients risk groups which are in the highest danger of decreased QoL. Our data indicate the need for psychological interventions.
\end{abstract}

Key words: psychodermatology, quality of life, itch, psoriasis.

\section{Introduction}

Psoriasis belongs to psychodermatological diseases, so both medical (e.g. disease severity and duration, pruritus) and psychological factors influence its course [1-3]. Psoriasis itself, considering it is a chronic, inflammatory and relapsing condition, can be a source of stress and can worsen patients' quality of life (QoL) [1, 3-10]. As a consequence it can lead to psychological conditions such as anxiety, depression and suicidal ideation [4, 5, 7, 11-13].

The symptom which significantly impairs QoL is itch [14-17]. It occurs in $60 \%$ to even $92 \%$ of psoriatics [16-19]. Itch impact on well-being can be moderated by disease severity, but also by psychological factors. Scratching can lead to increased focus on the sensation of itch and intensify it. On the other hand, this activity helps in reducing inner tension giving immediate sense of relief, working as a positive reinforcement of that behavior. As a result, a vicious cycle of itch-and-scratch appears which can be connected with feelings of losing control and sense of helplessness in confrontation with the pruritic disease. Subsequently, QoL is negatively affected [20-22]. But the disease does not have to lead to decreased well-being. Illness is an interaction between disease demands and personal resources (individual, environmental attributes and relation between them), which enhance effective coping strategies and can result in achieving own goals and meet important needs, so their role is worth deeper consideration [6, 7, 23-25].

\section{Aim}

The aim of the study was to estimate the relationship between medical (disease severity, itch) and psychological variables (disease coping strategies, QoL) in the psoriasis patients group.

\section{Material and methods}

The study comprises 60 psoriasis in-patients of the dermatological ward (30 females and 30 males). The

Address for correspondence: Alicja Ograczyk, Department of Psychodermatology, Medical University of Lodz, 251 Pomorska St, 92-213 Lodz, Poland, phone: +48 502099 388, e-mail: alicja-ograczyk@o2.pl Received: 18.07.2013, accepted: 27.08.2013. 
Table 1. Sociodemographic characteristics of the study group

\begin{tabular}{lc}
\hline Parameter & Result \\
\hline $\begin{array}{l}\text { Age, mean } \pm \text { SD (range) } \\
\text { [years] }\end{array}$ & $44.91 \pm 14.78(20-70)$ \\
\hline $\begin{array}{l}\text { Disease duration, mean } \\
\pm \text { SD (range) }\end{array}$ & $18.76 \pm 13.50$ (4 months - \\
\hline $\begin{array}{l}\text { Educational level, } n \text { (\%): } \\
\text { Primary }\end{array}$ \\
\hline Vocational & $2(3)$ \\
\hline Secondary & $18(30)$ \\
\hline University & $23(38)$ \\
\hline Civil status, $n$ (\%): & $17(29)$ \\
\hline Singles & $19(32)$ \\
\hline Married & $30(50)$ \\
\hline Widow/widower & $4(7)$ \\
\hline Divorced & $7(11)$ \\
\hline Residence place, $n(\%):$ & $45(75)$ \\
\hline City & $15(25)$ \\
\hline Countryside & \\
\hline
\end{tabular}

$N$-number of patients in the group, SD - standard deviation mean age was $44.91 \pm 14.78$ (range: $20-70$ years) and the average disease duration $18.76 \pm 13.50$ years (range: 4 months -54 years). Disease severity was assessed by a dermatologist and measured by the Psoriasis Area and Severity Index (PASI) with the mean result of $9.32 \pm 5.97$ (range: 0.6-27.4). Patients were recruited from October 2010 to June 2012. The study was approved by the Medical University of Lodz Bioethics Committee. Patients gave their informed consent to take part in the study. The detailed demographic characteristics of the patients are demonstrated in Table 1.

The following methods were employed in the study: 1. Authors' questionnaire consisting of clinical and demographic data.

2. Itch Severity Evaluation Questionnaire (Szepietowski, Reich, 2010) [26] - a method to estimate itch. It allows to measure not only global itch, but also itch characteristic regarding its intensity, range, duration (short episodes (< $10 \mathrm{~min}$ ), long episodes (> $10 \mathrm{~min}$ ), constant itch) and sleep disturbances caused by itch.

3. Coping with Skin Disease Scale SRS-DER (by Miniszewska, 2007) [23] - the scale evaluates stress coping strategies with dermatological disease; it consists of 3 subscales regarding strategies: a) helplessness/ hopelessness, b) fight spirit, c) distraction/catastrophization. The questionnaire involves 18 items equally for every subscale; each statement is evaluated on

Table 2. Quality of life, disease coping strategies and itch characteristics related to gender

\begin{tabular}{|c|c|c|c|c|c|c|}
\hline \multirow[t]{2}{*}{ Variables } & \multicolumn{2}{|c|}{ Women $(n=30)$} & \multicolumn{2}{|c|}{ Men $(n=30)$} & \multirow[t]{2}{*}{ Value of $t$} & \multirow[t]{2}{*}{ Value of $p$} \\
\hline & Mean & SD & Mean & SD & & \\
\hline \multicolumn{7}{|l|}{ QoL: } \\
\hline Symptoms & 21.57 & 4.82 & 18.07 & 3.96 & -3.07 & 0.003 \\
\hline Emotions & 31.27 & 10.35 & 26.97 & 7.98 & -1.80 & 0.08 \\
\hline Functioning & 33.53 & 9.49 & 30.53 & 9.02 & -1.26 & 0.21 \\
\hline Overall & 86.37 & 21.86 & 75.57 & 18.17 & -2.08 & 0.04 \\
\hline \multicolumn{7}{|l|}{ Disease coping strategies: } \\
\hline Helplessness/hopelessness & 12.47 & 3.92 & 11.67 & 4.00 & -0.78 & 0.43 \\
\hline Fight spirit & 19.26 & 2.92 & 18.23 & 2.90 & -1.38 & 0.17 \\
\hline Distraction/catastrophization & 16.27 & 3.46 & 15.10 & 3.02 & -1.39 & 0.17 \\
\hline \multicolumn{7}{|l|}{ Itch characteristics: } \\
\hline Itch range & 1.50 & 1.01 & 1.74 & 0.94 & 0.92 & 0.36 \\
\hline Itch severity & 2.60 & 1.48 & 2.57 & 1.61 & -0.08 & 0.93 \\
\hline Short itch episodes & 1.07 & 1.36 & 1.13 & 1.38 & 0.19 & 0.85 \\
\hline Long itch episodes & 0.53 & 1.17 & 0.60 & 1.33 & 0.21 & 0.84 \\
\hline Constant itch & 0.34 & 1.27 & 0.17 & 0.92 & -0.58 & 0.56 \\
\hline Itch-related sleeping disorders & 1.20 & 1.94 & 0.64 & 1.54 & -1.25 & 0.22 \\
\hline Global itch & 7.20 & 4.82 & 6.83 & 4.14 & -0.32 & 0.75 \\
\hline
\end{tabular}

SD - standard deviation, t-Student t-test, $p$ - significance level 
a four-point scale (definitely no, rather no, rather yes, definitely yes) and the results are summed up separately for three strategies; the higher the score, the more characteristic is the coping with the disease for the patient. The strategy fight spirit is thought to have positive meaning in the coping process, whereas helplessness/hopelessness and distraction/catastrophization are treated as non-adaptive ones.

4. SKINDEX-29 questionnaire (Chren et al., Polish adaptation Steuden, Janowski) $[27,28]$ - the method specific to the quality of life evaluation in dermatological patients ( $\mathrm{HRQOL})$. The scale involves 3 dimensions - disease symptoms, emotions and social functioning. The scores are obtained on a 5 -point scale. Lower results are an indicator of a higher QoL level.

\section{Statistical analysis}

The SPSS package for Windows (IBM SPSS Statistics 19) was used for statistical analysis. Mean (M) and standard deviation (SD) are presented. The distribution of the obtained results did not differ significantly from normal distribution. The Student's t-test ( $t$ ) and Pearson correlation $(r)$ were performed. The statistical significance level was set at $p<0.05$.

\section{Results}

Firstly we investigated the differences between males and females related to disease coping strategies, itch characteristics and QoL (Table 2). Females presented worse QoL considering physical symptoms and overall
Table 3. Correlations between disease coping strategies and QoL

\begin{tabular}{lccc}
\hline QoL & \multicolumn{3}{c}{ Disease coping strategies } \\
\cline { 2 - 4 } & $\begin{array}{c}\text { Helplessness/ } \\
\text { hopelessness }\end{array}$ & $\begin{array}{l}\text { Fight } \\
\text { spirit }\end{array}$ & $\begin{array}{c}\text { Distraction/ } \\
\text { catastrophization }\end{array}$ \\
\hline Symptoms & $0.34^{*}$ & 0.11 & $0.37^{\star}$ \\
\hline Emotions & $0.67^{*}$ & -0.22 & $0.47^{\star}$ \\
\hline Functioning & $0.53^{*}$ & $-0.27^{*}$ & $0.44^{*}$ \\
\hline Overall & $0.62^{*}$ & -0.22 & $0.50^{\star}$ \\
\hline
\end{tabular}

${ }^{*} p<0.05$

score. There were no differences related to disease coping strategies and itch characteristics.

The correlations between disease coping strategies, itch characteristics and QoL were evaluated by Pearson's $r$-ratio. Disease coping strategies related to the feeling of helplessness/ hopelessness and distraction/catastrophization appeared to be significantly and positively associated with all three SKINDEX subscales and the overall score, so they are connected with worse physical, emotional and social functioning. On the contrary, a fight spirit strategy negatively correlates with impairment in the social sphere, so the ones who apply this strategy can encounter less problems in their social life (Table 3).

When looking at any links between itch features and QoL (Table 4), we observed that itch severity, sleep disturbances as its consequences together with general itch were associated with worse physical functioning.

The correlations between disease coping strategies and itch features were revealed, namely the stronger

Table 4. Correlations between itch characteristics and QoL

\begin{tabular}{|c|c|c|c|c|c|c|c|}
\hline \multirow[t]{2}{*}{ QoL } & \multicolumn{7}{|c|}{ Itch characteristics } \\
\hline & Itch range & Itch severity & $\begin{array}{l}\text { Short itch } \\
\text { episodes }\end{array}$ & $\begin{array}{l}\text { Long itch } \\
\text { episodes }\end{array}$ & $\begin{array}{l}\text { Constant } \\
\text { itch }\end{array}$ & $\begin{array}{c}\text { Itch-related } \\
\text { sleeping disorders }\end{array}$ & Global itch \\
\hline Symptoms & 0.24 & $0.33^{*}$ & 0.18 & -0.09 & 0.21 & $0.36^{*}$ & $0.39^{\star}$ \\
\hline Emotions & -0.14 & 0.18 & 0.31 & -0.13 & -0.13 & 0.18 & 0.12 \\
\hline Functioning & -0.05 & 0.25 & 0.26 & -0.02 & -0.34 & 0.10 & 0.08 \\
\hline Overall & -0.02 & 0.27 & 0.29 & -0.09 & -0.16 & 0.21 & 0.19 \\
\hline
\end{tabular}

Table 5. Correlations between itch characteristics and disease coping strategies

\begin{tabular}{lccccccc}
\hline Disease coping strategies & \multicolumn{1}{c}{ Itch characteristics } \\
\cline { 2 - 8 } & $\begin{array}{c}\text { Itch } \\
\text { range }\end{array}$ & $\begin{array}{c}\text { Itch } \\
\text { severity }\end{array}$ & $\begin{array}{c}\text { Short itch } \\
\text { episodes }\end{array}$ & $\begin{array}{c}\text { Long itch } \\
\text { episodes }\end{array}$ & $\begin{array}{c}\text { Constant } \\
\text { itch }\end{array}$ & $\begin{array}{c}\text { Itch-related } \\
\text { sleeping disorders }\end{array}$ & $\begin{array}{c}\text { Global } \\
\text { itch }\end{array}$ \\
\hline Helplessness/hopelessness & -0.08 & 0.15 & 0.40 & -0.08 & -0.17 & 0.10 & -0.01 \\
\hline Fight spirit & -0.08 & $-0.28^{*}$ & $-0.37^{*}$ & 0.07 & 0.32 & -0.11 \\
\hline Distraction/catastrophization & -0.09 & 0.01 & 0.21 & 0.02 & -0.20 & 0.24 & 0.08 \\
\hline${ }^{*}<0.05$ & & & & & &
\end{tabular}


fight spirit, the less severe itch and less itch episodes were manifested (Table 5).

The relations between age, skin condition severity, disease duration and itch, coping strategies, QoL were also analyzed. It was manifested that older people are characterized by worse social functioning $(r=0.32, p=0.017)$. Age was related to a longer disease duration $(r=0.45$, $p<0.0001)$ and longer period of suffering from psoriasis results in more impairment in QoL generally $(r=0.30$, $p=0.024)$ and in social functioning $(r=0.34, p=0.010)$.

\section{Discussion}

Regarding the aim of our research, relations between skin status, itch, disease coping strategies and QoL were expected and finally they were observed.

The conducted study revealed differences in QoL regarding gender. It is worth underlining that both groups did not differ in terms of disease severity but women reported more troublesome physical symptoms and generally worse QoL. Similar results were obtained by other research groups [29-31]. However, some data are opposite $[6,7,32-34]$.

Our results demonstrated changes in QoL considering age. Older patients with a longer disease duration reported more difficulties in social functioning. There is no consistency of data regarding relationships between age, disease duration and QoL. Some authors reported results similar to ours $[3,6,7,33]$ whereas others noted opposite observations [30, 34].

The negative relation between itch and QoL was confirmed in our study. It regards itch severity, sleeping disorders caused by itch, global itch and physical component of QoL. Our results could suggest that disease severity enhances pruritus and in turn it impairs QoL, but the correlation between skin status and itch was not observed. It is probable that attentional focus on bodily sensations takes part in this process. It was confirmed that psoriasis patients in comparison to rheumatoid arthritis ones reacted to the histamine stimuli with a more intense itch response [35]. Higher sensitivity was associated with an increased focus on bodily sensations [36] which could maintain and exacerbate itch [36-38].

Our study also demonstrated sleep disturbances related to itch, which impairs QoL. Both sleep quantity and quality are affected. What is emphasized, sleep disturbances are frequently connected with depressive symptoms in psoriatics, so it is essential to be alert as a clinician when sleep problems occur $[39,40]$.

The link between itch and disease coping strategies was shown, so it is quite strong evidence for psychological factors contribution to itch mechanism. Fight spirit turned out to play a positive role in handling pruritus and it is associated with less intense itching and less frequent occurrence of short itch episodes. Self-control over pruritic sensations could have a significant meaning in that case $[14,16]$. When patients know how to cope, they do not feel helpless in confrontation with pruritus and can break an itch-and-scratch vicious cycle. Patients who participated in itch coping program presented an improvement in terms of better skin condition, less itching and scratching. These outcomes were maintained and even increased during follow-up periods ( 3 and 12 months later) [41]. It was marked that patients' self-efficacy in itch coping was enhanced. The QoL was improved, so such training can be strongly recommended for the patients.

Our study manifested many relationships between disease coping strategies and QoL. Feeling of being hopeless/ helpless correlates with all domains of QoL. This strategy is associated with lack of control over the disease, so negative illness aspects, such as its chronic course and unpredictability are emphasized. Correlations revealed the strongest association with the emotional subscale of QoL. The employment of this strategy can lead to depression. Being helpless and hopeless could also result in stronger feelings of stigmatization [6, 14, 24, 42, 43].

Distraction/catastrophization was also connected with overall QoL and all its dimensions. Extensive worrying about the disease-specific aspects can negatively affect the illness course [14, 22]. The avoidance of confrontation with health condition and limitations related to it, could increase disease-related stress [25]. So the non-adaptiveness of distraction/ catastrophization was confirmed.

Contrary to the above mentioned strategies, fight spirit turned out to be an effective disease coping strategy. It is strongly connected with the sense of control and the ability to live and handle the disease and treat it as a challenge worth investing the efforts. The involvement in treatment is stronger when this strategy is applied by the patient. The employment of fight spirit can lead to illness acceptance related to better well-being [6, 14, 32, 42, 44-47]. The doctor could enhance adaptive coping by involving his/her own patients in the treatment process and through proper educational activities. The supportive doctor-patient relation seems to be of key importance in the therapeutic plan and it can enhance compliance $[11,25,45]$.

\section{Conclusions}

The obtained results could help in identifying risk groups which are in the highest danger of QoL impairment development. On the basis of our investigations, psychological interventions should be addressed especially to female patients, to older ones with a long disease duration and psoriatics applying non-adaptive stress coping strategies - helplessness/hopelessness and distraction/catastrophization. Furthermore, availability of psychological programs such as itch/stress-coping trainings could lead to better pruritus/stress management and increased self-efficacy resulting in QoL improvement. 


\section{Acknowledgments}

This study was supported by the statutory grant of the Medical University of Lodz no. 503/1-137-04/503-01.

\section{References}

1. Zalewska-Janowska A. Psychodermatology in allergology [Polish]. Alergia Astma Immunologia 2010; 15: 109-17.

2. Mazzotti E, Mastroeni S, Lindau J, et al. Psychological distress and coping strategies in patients attending a dermatology outpatient clinic. J Eur Acad Dermatol Venereol 2012; 26: 746-54.

3. Rzepa T, Szepietowski J, Żaba R. Psychological and medical aspects of skin diseases [Polish]. Cornetis, Wrocław 2011.

4. Palijan TZ, Kovacević D, Koić E, et al. The impact of psoriasis on the quality of life and psychological characteristics of persons suffering from psoriasis. Coll Antropol 2011; 35 (Suppl. 2): 81-5.

5. Sampogna F, Tabolli S, Abeni D. Living with psoriasis: prevalence of shame, anger, worry, and problems in daily activities and social life. Acta Derm Venereol 2012; 92: 299-303.

6. Miniszewska J, Juczyński Z, Ograczyk A, et al. Health-related Quality of Life in Psoriasis: important role of personal resources. Acta Derm Venereol 2013; 93: 551-6.

7. Miniszewska J, Chodkiewicz J, Ograczyk A, et al. Optimism as a predictor of health-related quality of life in psoriatics. Postep Derm Alergol 2013; 30: 91-5.

8. Evers AWM, Duller P, van de Kerkhof PCM, et al. The impact of chronic skin disease on daily life (ISDL): a generic and dermatology-specific health instrument. Br J Dermatol 2008; 158: 101-8.

9. Świnoga M, Kłos M, Miniszewska J, et al. Health-related quality of life in dermatological and allergo-dermatological patients. Postep Derm Alergol 2012; 29: 69-73.

10. Wielowieyska-Szybińska D, Wojas-Pelc A. Psoriasis: course of disease and treatment. Postep Derm Alergol 2012; 29: $118-22$.

11. Gordon-Elliot JS, Muskin PR. Managing the patient with psychiatric issues in dermatologic practice. Clin Dermatol 2013; 31: 3-10.

12. Picardi A, Lega I, Tarolla E. Suicide risk in skin disorders. Clin Dermatol 2013; 31: 47-56.

13. Tyc-Zdrojewska E, Trznadel-Grodzka E, Kaszuba A. The impact of chronic skin diseases on patient's quality of life [Polish]. Dermatol Klin 2011; 13: 155-60.

14. Verhoeven EW, de Klerk S, Kraaitmaat FW, et al. Biopsychological mechanism of chronic itch in patients with skin diseases: a review. Acta Derm Venereol 2008; 88: 211-8.

15. Verhoeven EW, Kraaitmaat FW, van de Kerkhof PC, et al. Prevalence of physical symptoms of itch, pain and fatigue in patients with skin diseases in general practice. J Br Dermatol 2007; 156: 1346-9.

16. Yosipovitch G, Goon A, Wee J, et al. The prevalence and clinical characteristics of pruritus among patients with extensive psoriasis. Br J Dermatol 2000; 143: 969-73.

17. Prignano F, Ricceri F, Pescitelli L, et al. Itch in psoriasis: epidemiology, clinical aspects and treatment options. Clin Cosmet Investig Dermatol 2009; 2: 9-13.

18. Sampogna F, Gisondi P, Melchi CF, et al. Prevalence of symptoms experienced by patients with different clinical types of psoriasis. Br J Dermatol 2004; 151: 594-9.
19. Gupta MA, Gupta AK, Kirkby S, et al. Pruritus in psoriasis. A prospective study of some psychiatric and dermatologic correlates. Arch Dermatol 1988; 124: 1052-7.

20. Schneider G. Psychosomatic aspects and psychiatric conditions. In: Pruritus. Misery L, Stander S (eds). Springer-Verlag, London 2010.

21. Tey HL, Wallengren J, Yosipovitch G. Psychosomatic factors in pruritus. Clin Dermatol 2013; 31: 31-40.

22. Verhoeven L, Kraaimaat FW, Duller P, et al. Cognitive, behavioral and physiological reactivity to chronic itching: analogies to chronic pain. Int J Behav Med 2006; 13: 237-43.

23. Miniszewska J. Personal resources as determinants of quality of life in psoriasis patients. PhD dissertation. KUL, Lublin 2007.

24. Ograczyk A, Malec J, Miniszewska J, et al. Psychological aspects of atopic dermatitis and contact dermatitis: stress doping strategies and stigmatization. Postep Derm Alergol 2012; 29: 14-8.

25. Heszen I, Sęk H. Health psychology [Polish]. PWN, Warsaw 2008.

26. Szepietowski J, Reich A. Itch. Patomechanism, clinics, treatment [Polish]. Termedia, Poznan 2010.

27. Chren MM, Lasek RJ, Quinn LM, et al. Skindex, a quality-of-life measure for patients with skin diseases: reliability, validity and responsiveness. J Invest Dermatol 1996; 107: 707-13.

28. Steuden S, Janowski K. The employment of Skindex questionnaire to measure quality of life in patients with psoriasis [Polish]. Przegl Dermatol 2001; 88: 41-8.

29. Dalgard F, Svensson A, Holm J, et al. Self-reported skin morbidity among adults: associations with quality of life and general health in a Norwegian survey. J Invest Dermatol 2004; 9: 120-5.

30. Zachariae R, Zachariae H, Ibsen HHW, et al. Psychological symptoms and quality of life of dermatology outpatients and hospitalized dermatology patients. Acta Derm Venereol 2004; 84: 205-12.

31. Jankowiak B, Sekmistrz S, Kowalewska B, et al. Satisfaction with life in a group of psoriasis patients. Postep Derm Alergol 2013; 30: 85-90.

32. De Korte J, Sprangers MAG, Mombers FMC, et al. Quality of life in patients with psoriasis: a systematic literature review. J Invest Dermatol Symposium Proceedings 2004; 2: 140-7.

33. Kostyła M, Tabała K, Kocur J. Illness acceptance degree versus intensity of psychopathological symptoms in patients with psoriasis. Postep Derm Alergol 2013; 30: 134-9.

34. Basińska MA, Szymańska L. The relation between mood and disease features in psoriasis patients [Polish]. Przegl Dermatol 2013; 100: 146-53.

35. Van Laarhoven AIM, Kraaimaat FW, Wilder-Smith $\mathrm{OH}$, et al. Sensitivity to itch and pain in patients with psoriasis and rheumatoid arthritis. Exp Dermatol 2013; 22: 530-4.

36. Van Laarhoven AIM, Kraaimaat FW, Wilder-Smith OH, et al. Role of attentional focus on bodily sensations in sensitivity to itch and pain. Acta Derm Venereol 2010; 90: 46-50.

37. Van Laarhoven AIM, Kraaimaat FW, Wilder-Smith $\mathrm{OH}$, et al. Generalized and symptom-specific sensitization of chronic itch and pain. J Eur Acad Dermatol Venereol 2007; 21: 1187-92.

38. Ikoma A, Fartasch M, Heyer G. Painful stimuli evoke itch in patients with chronic pruritus: central sensitization for itch. Neurology 2004; 62: 212-7.

39. Shutty BG, West C, Huang KE, et al. Sleep disturbances in psoriasis. Dermatol Online J 2013; 19: 1. 
40. Mostaghimi L. Prevalence of mood and sleep problems in chronic skin diseases: a pilot study. Cutis 2008; 14: 267-71.

41. Evers AWM, Duller P, De Jong EMGJ, et al. Effectiveness of a multidisciplinary itch-coping training programme in adults with atopic dermatitis. Acta Derm Venereol 2009; 89: 57-63.

42. Evers AWM, Lu Y, Duller P, et al. Common burden in chronic skin disease? Contributors to psychological distress in adults with psoriasis and atopic dermatitis. Br J Dermatol 2005; 152: 1275-81.

43. Lu Y, Duller P, van der Valk PGM, et al. Helplessness as predictor of stigmatization in patients with psoriasis and atopic dermatitis. Dermatol Psychosom 2003; 4: 146-50.

44. Zalewska A, Miniszewska J, Chodkiewicz J, et al. Acceptance of chronic illness in psoriasis vulgaris patients. J Eur Acad Dermatol Venereol 2007; 21: 235-42.

45. Olchowska-Kotala A. Patient's illness perception [Polish]. Lekarz Rodzinny 2012; 12: 936-40.

46. Evers AWM, Kraaimaat FW, van Lankveld W, et al. Beyond unfavourable thinking: the illness cognition questionnaire for chronic diseases. J Consult Clin Psychol 2001; 69: 1026-36.

47. King G, Cathers T, Brown E, et al. Turning points and protective processes in the lives of people with chronic disabilities. Qual Health Res 2003; 13: 184-206. 